\title{
Infantile glaucoma
}

\section{Steroid testing in parents of affected children}

\author{
D. A. LEIGHTON AND C. I. PHILLIPS \\ Department of Ophthalmology, University of Manchester, and Manchester Royal Eye Hospital
}

An important hereditary influence in open-angle glaucoma is already known to exist. At present the most powerful means of making manifest the presence of such a trait is probably the application of topical cortisone, which produces a marked rise in ocular tension in susceptible individuals, i.e. principally in cases of open-angle glaucoma (Armaly, 1963) and their relatives (Becker and Hahn, 1964). The magnitude and frequency of this rise in open-angle glaucoma has been shown to be greater than in a control sample (Armaly, 1965). Armaly (1966) has also shown that the ocular hypertensive response is itself genetically determined, possibly as a recessive trait.

Since the parents of children with infantile glaucoma are presumably heterozygous for the gene responsible, the condition being recessive, it seemed worthwhile to test their response to topical dexamethasone in order to establish whether or not the carrier state of a gene producing infantile glaucoma shares with open-angle glaucoma the property of a hypertensive response.

\section{Methods}

Index patients were thirteen males and five females with infantile glaucoma. Parents of these children were invited to attend for examination. In all, 35 parents (i.e. seventeen marital pairs and one mother) were seen and examined at an initial visit, and 28 re-attended after a course of guttae dexamethasone $0 \cdot 1$ per cent. three times a day for 3 weeks.

At the first visit the following procedure was carried out:

(1) A general, ocular, and family history was taken.

(2) The optic discs and fundi were examined.

(3) A slit-lamp examination was performed.

(4) Applanation tensions, i.e. three readings, were taken from each eye, right eye first, the middle reading in order of magnitude being noted.

(5) The angles were examined with a gonioscope.

Subjects were then given guttae dexamethasone* $0 \cdot 1$ per cent. to be instilled three times daily into one eye for 3 weeks, and were asked to re-attend after that time for repeat applanation tensions. Only 28 out of the possible total of 36 completed the course of guttae dexamethasone. The reasons for this discrepancy are set out overleaf: 


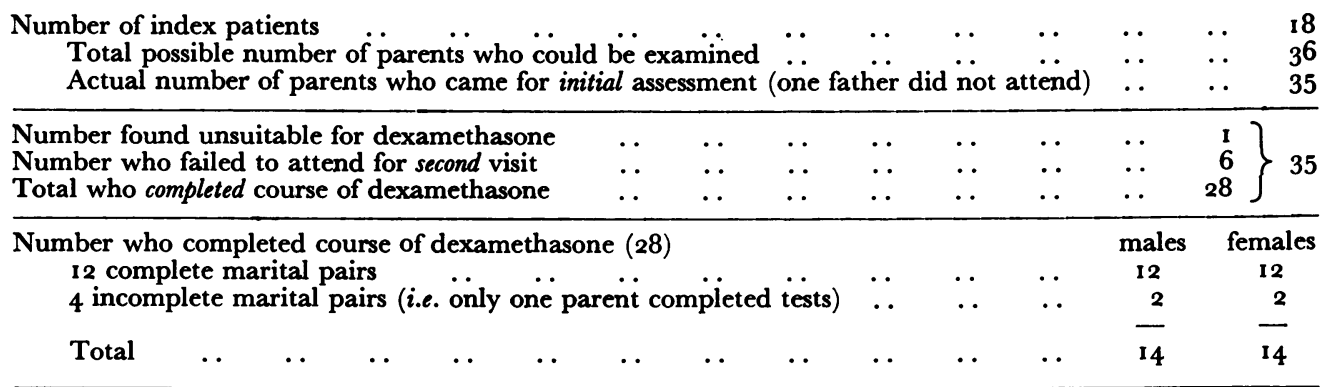

24 controls from the Outpatient Department, parents of patients who had squints, were matched for sex and age (within the range +5 to -6 years; the average age difference was minus 0.5 years) with 24 of the parents of affected children, and completed the same course of dexamethasone. It was difficult to achieve 28 controls because defaulting was common after the initial agreement to use dexamethasone.

\section{Results}

\section{(I) HISTORY \\ (a) Consanguinity}

Perhaps rather surprisingly, none was noted in any of the parents interviewed.

(b) Family history

In the eighteen families investigated in this way, there were 2 I siblings of affected children, and none of these had glaucoma. In only one family was there a second affected member and this was an example of dominance or pseudo-dominance (Waardenburg, Franceschetti, and Klein, 1961), the male index patient having had a daughter with unilateral infantile glaucoma.

\section{(2) RESPONSE OF OCULAR TENSION TO GUTTAE DEXAMETHASONE}

The mean tension in the test eyes of parents of patients with infantile glaucoma was $16.32 \mathrm{~mm}$. $\mathrm{Hg}$ applanation before and $18 \cdot 36 \mathrm{~mm}$. $\mathrm{Hg}$ after dexamethasone: the corresponding figures for the controls were $15 \cdot 08$ and $18 \cdot 63$ (Table I).

Table I Ocular tension (mm. Hg applanation) before and after a 3-week course of dexamethasone

\begin{tabular}{|c|c|c|c|c|c|c|c|c|c|}
\hline \multicolumn{2}{|l|}{ Visit } & \multicolumn{4}{|l|}{$\mathbf{I}$} & \multicolumn{4}{|l|}{2} \\
\hline \multirow{2}{*}{\multicolumn{2}{|c|}{ Eye }} & \multicolumn{2}{|l|}{ Test } & \multicolumn{2}{|c|}{ Contralateral } & \multicolumn{2}{|l|}{ Test } & \multicolumn{2}{|c|}{ Contralateral } \\
\hline & & Mean & $S D$ & Mean & $S D$ & Mean & $S D$ & Mean & $S D$ \\
\hline Series & $\begin{array}{l}28 \text { parents } \\
24 \text { controls }\end{array}$ & $\begin{array}{l}16 \cdot 32 \\
15 \cdot 08\end{array}$ & $\begin{array}{l}3 \cdot 51 \\
3 \cdot 62\end{array}$ & $\begin{array}{l}16 \cdot 29 \\
14 \cdot 92\end{array}$ & $\begin{array}{l}3 \cdot 33 \\
3 \cdot 11\end{array}$ & $\begin{array}{l}18 \cdot 36 \\
18 \cdot 63\end{array}$ & $\begin{array}{l}3 \cdot 68 \\
2 \cdot 89\end{array}$ & $\begin{array}{l}16 \cdot 11 \\
14 \cdot 54\end{array}$ & $\begin{array}{l}3.53 \\
4.05\end{array}$ \\
\hline
\end{tabular}

SD $=$ Standard deviation

Of the 28 parents and 24 controls, the tension fell in five and three instances respectively and remained the same in three and one. Inadequate instillation of drops may, of course, be the explanation for the lack of rise in these cases. These differences in the direction of change in tension between parents and controls were statistically non-significant $\left(\chi^{2}=\right.$ $\mathrm{I} \cdot 54 ; \mathrm{n}=2 ; 0.3<\mathrm{p}<0.5)$. 
These observations are shown in the histograms in Figs I and 2 as a "shift to the right". The standard deviations before and after treatment were similar.
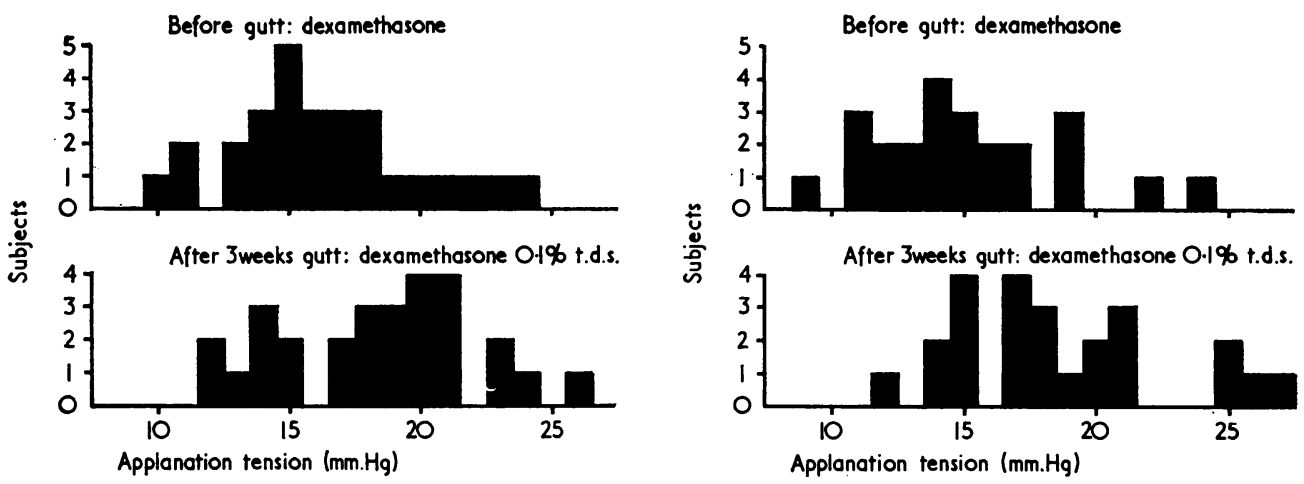

FIG. I Applanation tensions of parents of affected children before and after guttae dexamethasone $0 \cdot$ I per cent. three times daily for 3 weeks. Note a "shift to the right", indicating an ocular hypertensive response, which is quantitatively similar to that in Fig. 2

FIG. 2 Applanation tensions of controls before and after guttae dexamethasone $0 \cdot 1$ per cent. three times daily for 3 weeks. Note a "shift to the right", indicating an ocular hypertensive response, which is quantitatively similar to that in Fig. I

In a Wilcoxon Matched Pairs Signed Ranks Test (Siegel, 1956), the rise in tension was significant in the parents of affected children and also in the controls $(\mathrm{P}<\mathrm{O} \cdot \mathrm{OI})$ (See Table II).

Table II Statistical analysis of changes in ocular tension (see Table I) of test and control (contralateral) eyes after a 3-week course of dexamethasone (Wilcoxon score)

\begin{tabular}{|c|c|c|c|c|c|c|c|c|}
\hline \multirow{2}{*}{ Eye } & & \multirow{2}{*}{$\begin{array}{l}\text { Change in } \\
\text { ocular } \\
\text { tension }\end{array}$} & \multicolumn{6}{|l|}{ Series } \\
\hline & & & $T$ & $T(0.05)$ & $\mathrm{P}$ & $T$ & $T(0 \cdot 05)$ & $\vec{P}$ \\
\hline ( $\mathbf{I})$ & Test & Rise & $5^{1 \frac{1}{2}}$ & 89 & $<\cdot 01 *$ & $3^{2}$ & 73 & $<\cdot \mathrm{OI}^{*}$ \\
\hline$(2)$ & $\begin{array}{l}\text { Test } \\
\text { "allowing for change in } \\
\text { tension of contralateral eye" }\end{array}$ & Rise & 30 & 81 & $<\cdot 0 I^{*}$ & 33 & 89 & $<\cdot$ OI $^{*}$ \\
\hline (3) & Contralateral untreated & Fall & I 18 & 66 & $>\cdot 05$ & 83 & $5^{2}$ & $>\cdot 05$ \\
\hline
\end{tabular}

* difference statistically significant $(\mathrm{P}<0.01)$.

$\mathrm{T}(0.05)$ refers to the Wilcoxon score for a probability of $\mathrm{P}=0.05$ for each test.

Table I shows that, in the contralateral untreated eyes, the ocular tension tended to fall, though not significantly (Table II). This fall in tension of the untreated eye would presumably have been paralleled by a fall in the tension of the test eye if dexamethasone had not been given, and so the fall in the former between Visit I and Visit 2 was taken into account in estimating the rise in tension of the test eye after dexamethasone; e.g. if the tension in the contralateral eye had fallen from, say, I 3 to I I $\mathrm{mm}$. $\mathrm{Hg}$ between Visits I and 2 , and the tension in the test eye had risen from $\mathrm{I} 4$ to $18 \mathrm{~mm}$. $\mathrm{Hg}$, then the rise in the latter, taking account of the fall in the former, would have been taken as $(4+2)=6 \mathrm{~mm}$. $\mathrm{Hg}$. A Wilcoxon Test was done on the results expressed in this way between test eyes and untreated eyes in each individual, and again the results were significant for a rise in tension at $\mathrm{P}<\mathrm{O} \cdot \mathrm{OI}$ in both parents and controls (Table II). 
However, the magnitude of the rise in pressure in $(a)$ parents as compared with $(b)$ controls did not differ significantly (to a Mann-Whitney U Test (Siegel, 1956) Z $=1$ ' 32 ; 음 $\mathrm{U}=264 ; \mathrm{P}=0.0934)$. To a Wilcoxon Test, the 24 parents having been carefully matched with 24 of the controls, the absence of a significant difference in the magnitude of $\stackrel{\vec{D}}{\stackrel{D}{\circ}}$ the dexamethasone response was confirmed $(T=88$; $T$ for $P=0.05$ would have been $66 ; \mathrm{P}>0.05)$. Similarly, there was no significant sex difference in the response to dexamethasone.

(3) ANGLE OF ANTERIOR GHAMBER

Although one might have suspected that the parents of children with infantile glaucoma would have abnormal tissue in the angles revealing their heterozygous or carrier state, with only one exception, none was present. Angle appearances, therefore, seem to have no value in the detection of the carrier state.

\section{Discussion}

No toxic effects of dexamethasone were noted.

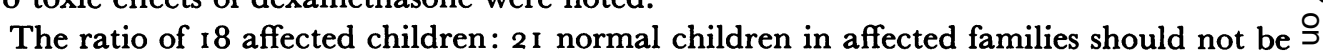
interpreted as favouring a dominant heredity, or as contradicting the generally accepted recessive pattern with a 40 to 60 per cent. penetrance (Waardenburg, Franceschetti, and Klein, I 96r). Of the 2 I siblings of patients, only two were younger than the index patients. This is probably related to the fact that parents of affected children were informed early in the treatment of their child that, although some cases may not be hereditary, there was statistical evidence that a risk existed to further children of the order of $I$ in 8 (recessive gene with 50 per cent. penetrance). If the parents decide that such a risk is too great, only one abnormal child is likely in each family, and this, coupled with the small size of the modern family, must increase the expected I : 8 ratio of affected to unaffected children in affected sibships.

The sex ratio of affected children (1 3 males : 5 females) favours males and this has $\overrightarrow{\overrightarrow{0}}$ frequently been found in other series (Shaffer, I 967 , mentions 70 per cent.); the sex ratio of their $2 \mathrm{I}$ unaffected siblings was 8 males : I 3 females. This sex difference was statistically significant $\left(\chi^{2}=4.55 ; n=1 ; 0.02<\mathrm{P}<0.05\right)$.

\section{Summary}

The response of ocular tension to guttae dexamethasone $0 \cdot$ I per cent. instilled three times daily for 3 weeks was similar in (a) parents of children with infantile glaucoma and $(b)$ controls who had been closely matched for age and sex.

Accordingly, as judged by the dexamethasone response, the genetic carrier state for infantile glaucoma is not related to open-angle glaucoma.

\section{References}

ARmaly, м. F. (1963) Arch. Ophthal. (Chicago), 70, 492

- (1965) Invest. Ophthal., 4, 187 ( (1966) Arch. Ophthal. (Chicago), 75, 32

BEcker, B., and haHn, к. A. (1964) Amer. 7. Ophthal., 57, 543

SIEGEL, S. (1956) “Nonparametric Statistics for the Behavioural Sciences”, pp. 75, I16. McGraw-

Hill, New York, London

SHAFFER, R. N. (1967) Trans. ophthal. Soc. U.K., 87, 581

WAARDENBURG, P. J., FRANCESchetti, A., and klein, D. (196i) “Genetics and Ophthalmology”, vol. I, pp. $5^{89}, 5^{87}$. Blackwell Scientific Publications, Oxford 